\title{
Estratégias periféricas sessenta anos depois do acordo de Bretton Woods
}

\author{
ANDRÉ MOREIRA CUNHA*
}

Peripheral strategies sixty years after the Bretton Woods agreement. After sixty years, the Bretton Woods Agreement continuous to be a reference for the debates concerning institutional organization of the international monetary system. This paper compares some features of the arrangements that have emerged in that context with the recent wave of institutional reforms in the international financial architecture. We explore some arguments suggesting that, in an instable financial environment, is possible to envisage a strong rationality in strategies for emerging economies associated with a more active capital flows and exchange rate management. Apparently, those strategies are not dissimilar to the ones today's advanced countries had used in Bretton Woods Era.

Key-words: Bretton Woods Agreement, capital flows and exchange rate management, emerging economies.

JEL classification: P16.

\section{INTRODUÇÃO}

Nas últimas décadas, vários países asiáticos, aqui agregados sob o termo Ásia em Desenvolvimento, ${ }^{1}$ lograram alcançar um ritmo acelerado de crescimento econômico, com avanços simultâneos nas áreas sociais e na manutenção do quadro de relativa estabilidade macroeconômica. Tal sucesso destaca-se ain-

\footnotetext{
* Professor do Departamento de Economia da UFRGS e Pesquisador do CNPQ. E-mail: amcunha@hotmail.com. Agradeço ao apoio de pesquisa do bolsista PIBIC-CNPQ, Henrique Renck. Esta é uma versão condensada do texto apresentado no XXXII Encontro Nacional da ANPEC. Agradeço aos comentários dos(as) pareceristas anônimos(as) que, como de praxe, estão isentos dos equívocos do autor. As citações em língua estrangeira são traduções livres do autor. Submetido: janeiro 2005; aceito: agosto 2005 .
}

${ }^{1}$ Esse tem sido o termo empregado pelo FMI em suas publicações mais recentes, especialmente nos World Economic Outlook. 
da mais quando se compara o desempenho de outras regiões, como a América Latina, a África e parte dos países do antigo bloco socialista. Em 1997, a crise financeira que atingiu aquela região levantou uma série de suspeitas sobre as pretensas virtudes do que se costumava chamar de "modelo asiático", normalmente associado aos casos do Japão, Coréia e Taiwan, e caracterizado por uma presença marcante da ação estatal na promoção de estratégias nacionais de desenvolvimento. Passou-se a utilizar a expressão crony capitalism ("capitalismo de compadres") para designar aquilo que se apontava ser um conjunto de relações espúrias entre o Estado e o setor privado, buscando-se reverter a visão positiva que se estabelecera na literatura ${ }^{2}$ sobre as políticas industriais, comerciais e tecnológicas que envolviam uma vinculação estreita entre aqueles setores (Radalet \& Sachs, 1998; Stiglitz, 2002). É bem verdade que a generalização do "modelo asiático" não é uma expressão exata da experiência histórica recente na região, onde as economias retardatárias, como Malásia, Indonésia, Tailândia, Filipinas, entre outras, estavam distantes de reproduzir elementos centrais do sucesso dos países mais avançados, como a existência de burocracias meritocráticas relativamente isoladas de pressões políticas espúrias (World Bank, 1993; Jomo,1996)

Nos anos que se seguiram à crise financeira, a surpreendente recuperação da região e o dinamismo apresentado por China e Índia fizeram com que os olhares dos especialistas se mantivessem fixos em direção ao oriente. Até porque, eram cada vez mais fortes os sinais de que o ciclo recente de liberalização econômica, especialmente em sua dimensão financeira, não fora capaz de gerar um processo mais equilibrado de crescimento na periferia capitalista. Pelo contrário, as evidências empíricas sugeriam que a globalização financeira, com suas promessas de crescimento, havia redundado apenas em mais instabilidade, conforme indicam estudos recentes realizados no FMI (IMF, 2001; Edison et al., 2002 e Prasad et al., 2003). Mais uma vez, o desempenho dos países periféricos mostrava-se desigual. $\mathrm{Na}$ Ásia em Desenvolvimento, mesmo com a crise de 1997, logrou-se sustentar um ritmo superior de crescimento, com diversos países utilizando estratégias macroeconômicas pouco alinhadas às sugestões que emanam de Washington e WallStreet. Pelo contrário, ao reproduzir um padrão de gestão dos fluxos financeiros, do câmbio e das reservas oficiais, por alguns considerado do tipo "mercantilista" 3 (Goldstein, 2003; Bergsten, 2004; Eichengreen, 2004) e, por outros, uma reprodução do espírito de "Bretton Woods" (Dooley et al., 2003 e 2004), alguns países asiáticos deram claros sinais de que não estavam dispostos a aceitar, passivamen-

\footnotetext{
${ }^{2}$ Algo reconhecido pelo próprio Banco Mundial, para o caso de Japão, Coréia e Taiwan, em seu estudo clássico sobre a região (World Bank, 1993).

${ }^{3}$ A revista The Economist tem cunhado de "mercantilista" a estratégia de muitos países asiáticos de acumular reservas oficiais, especialmente em ativos denominados em dólares norte-americanos, como contrapartida dos seus superávits comerciais, recentemente potencializados por moedas que, para muitos analistas, estariam artificialmente depreciadas. Ver, por exemplo: "Fear of Floating", 10/07/2003; "Oriental mercantilists", 18/09/2003; "Let the dollar drop", 05/02/2004.
} 
te, a internalização dos ciclos financeiros feast or famine ${ }^{4}$ que presidem a dinâmica recente das finanças globalizadas e desregulamentadas. ${ }^{5}$

Nesse contexto, o presente trabalho parte das observações de Dooley et al. $(2003,2004)$ acerca da racionalidade daquilo que aqui denominamos de "estratégia asiática" ${ }^{\circ}$, e que implica a busca de se preservar graus de liberdade para gestão macroeconômica em um ambiente de volatilidade financeira. Segundo aqueles autores, tal estratégia reproduziria a experiência de muitos países centrais no período de vigência do Acordo de Bretton Woods, firmado em 1944. Tendo por referência os sessenta anos de sua celebração, procura-se pontuar as semelhanças e diferenças entre dois momentos históricos de busca de ordenação das relações econômicas internacionais: a construção do ambiente institucional do pós-guerra e a tentativa de enfrentamento das crises financeiras da década de 1990. Assim, mais do que um retorno ao relevante tema dos modelos alternativos de desenvolvimento, o que remeteria a uma discussão mais estrutural, pretende-se aqui verificar os elementos principais do ajuste das estratégias dos países asiáticos no período que se seguiu à crise de 1997. Enfatiza-se a noção de que há tensão permanente entre a tendência à internacionalização das relações econômicas - o que reduz as margens de manobra para o exercício de políticas econômicas soberanas, porque voltadas ao atendimento de objetivos determinados por "centros nacionais de decisão" - e a busca de se ganhar novamente certa autonomia, em um ambiente externo instável, dominado por uma nova ordem financeira internacional de recorte liberal. Compara-se a trajetória asiática com a latino-americana, para o período recente de crises financeiras e reformas na arquitetura financeira internacional.

Além desta introdução, os argumentos estão organizados da seguinte forma. Parte-se de um retorno ao período do Acordo de Bretton Woods, para lembrar que os países centrais utilizaram, quando lhes era conveniente, estratégias semelhantes àquelas agora empregadas pelos asiáticos. A seguir são avaliadas as características mais marcantes do ciclo recente de expansão e contração das finan-

\footnotetext{
${ }^{4}$ Desde IMF (2003, apêndice do capítulo III), o Fundo tem utilizado a expressão "feast or famine" para designar os cada vez mais curtos ciclos de expansão e contração da liquidez financeira internacional. As fases feast determinam a entrada maciça de recursos na periferia. As fases famine caracterizam-se por uma menor propensão dos investidores a correr riscos e comprar ativos nos mercados emergentes. Nos dois casos, nem sempre há uma correlação estreita entre as decisões de investimento/desinvestimento e os fundamentos econômicos dos emergentes. Tendem a predominar "manias especulativas”, nos moldes da análise clássica de Kindleberger (2000).

${ }^{5}$ Para uma crítica do modelo de crescimento com base no endividamento externo nos marcos atuais de globalização das finanças internacionais ver, por exemplo, Belluzzo \& Coutinho (1996), BresserPerreira \& Nakano (2002).

${ }^{6}$ Dooley et al. (2003) não empregam tal termo. Eles identificam dois conjuntos de países: (1) o bloco 'trade-account', em que predominam os países asiáticos, que adotam estratégias de superávits em conta corrente, acúmulo de elevadas reservas em moeda forte, e gestão ativa do câmbio e dos fluxos financeiros; (2) o bloco capital-account, característico dos países latino-americanos, marcado por políticas de câmbio flutuante e um grau elevado de abertura financeira.
} 
ças internacionais, com ênfase para a tentativa de se adaptar as instituições que governam as relações entre os diversos atores privados e oficiais, no que se convencionou denominar de reformas na arquitetura financeira internacional (AFI, de agora em diante). Ressalta-se o caráter conservador destas. Por fim, são analisadas as estratégias periféricas de adaptação frente à nova ordem financeira internacional, com ênfase na comparação entre Ásia e América Latina. Seguem algumas considerações finais.

\section{DE BRETTON WOODS AO RETORNO DAS FINANÇAS GLOBALIZADAS E DESREGULAMENTADAS}

Há sessenta anos celebrou-se o Acordo de Bretton Woods, que deu vida ao que muitos consideram o mais bem-sucedido arranjo institucional das finanças internacionais dos últimos 150 anos. Em suas duas décadas e meia de funcionamento foi possível recuperar os fluxos de comércio sob bases multilaterais, reconstruir a Europa e o Japão, avançar na industrialização periférica e consolidar uma nova visão de complementaridade entre as ações dos estados nacionais e dos mercados. Considerando-se o desempenho macroeconômico, a "idade de ouro" das décadas de 1950 e 1960 testemunhou taxas recordes de crescimento da renda, com a manutenção de uma relativa estabilidade, tanto nas economias centrais, quanto em parcela significativa da periferia. ${ }^{7}$

A desconfiança nas propriedades auto-reguladoras dos mercados e a força das idéias de planejamento e intervenção do Estado na economia - legitimadas pela crise liberal e pelo sucesso das experiências soviética, do New Deal e do esforço de guerra - foram moldando o ambiente intelectual e político que deu luz ao Acordo de Bretton Woods. ${ }^{8}$ Dele emergiu uma nova ordem financeira internacional (Block, 1977), que procurava combinar a estabilidade propiciada pelo regime de câmbio fixo do antigo padrão ouro, com a flexibilidade requerida por

\footnotetext{
${ }^{7}$ Entre 1950 e 1973, o PIB per capita mundial cresceu 2,9\% ao ano, mais do que o dobro dos cerca de 1,3\% ao ano de crescimento nos períodos 1870-1913 e 1973-1998. As exportações expandiramse ao ritmo anual médio de $7,9 \%$, contra os $3,4 \%$ do período do padrão ouro e os $5,1 \%$ do último quartel do século XX. Na Europa Ocidental, a taxa de desemprego média, entre 1950 e 1973, foi de $2,6 \%$ ao ano, passando para $6 \%$ nos anos $1970,9 \%$ na década de 1980 , atingindo $11 \%$ entre 1994 e 1998. Na América do Norte e no Japão, também houve uma aceleração do desemprego no mesmo período. A inflação manteve-se entre 3\% (média da América do Norte) e 5\% (média japonesa) nos países industrializados no período do Acordo, acelerando nos anos 1970 e recuando nas décadas seguintes - para níveis médios na casa de $2 \%$ ao ano nas economias avançadas. A produtividade do trabalho cresceu duas vezes mais nas décadas que se seguiram ao final da Segunda Grande Guerra do que no último quartel do século XX. Este desempenho superior também pode ser verificado em um recorte regional, especialmente se tomarmos o caso das economias latino-americanas, e mesmo entre as asiáticas, que também experimentaram um boom no final do século XX (Maddison, 2001).

${ }^{8}$ Da vasta bibliografia sobre este tema, trabalhou-se aqui com as seguintes referências: Block (1977), De Cecco (1979), Eichengreen (1996), Helleiner (1994), Mikesell (1996), Lastra (2000), Skidelsky (1999 e 2000) e Boughton (2002).
} 
governos nacionais que passaram a assumir como dever a manutenção do pleno emprego, o que gerava a necessidade de maior autonomia na condução dos instrumentos de política econômica. Ademais, com a criação do Fundo Monetário Internacional (FMI), pretendeu-se estabilizar os processos de ajuste das contas externas, de modo a não se retornar às políticas de desvalorizações competitivas e protecionismo comercial.

O sistema Bretton Woods (SBW, de agora em diante) representou uma negação de pelos menos três dos fundamentos que sustentaram a ordem liberal do padrão ouro": (i) o câmbio fixo tornou-se "ajustável"; (ii) limitou-se fortemente a livre conversibilidade da conta capital e, na prática dos anos de "escassez de dólares" do imediato pós-guerra, foram toleradas restrições na conta corrente; (iii) foi criada uma instituição multilateral, o FMI, com mandato para monitorar as economias dos países-membros, atuando, também, como fonte oficial de liquidez para economias com dificuldades para fechar o balanço de pagamentos. A solução do câmbio fixo "porém ajustável" nasceu de uma síntese entre a posição norte-americana, que enfatizava a "volta ao ouro", no sentido da existência de um mecanismo estreito de fixação do valor relativo das moedas domésticas, e a visão britânica, contrária ao retorno dos ajustes deflacionários (Mikesell, 1996; Skidelsky, 2000; Boughton, 2002).

Entre a instabilidade dos anos do entre guerras e a rigidez do padrão ouro, buscou-se um meio termo, em que os países signatários do Acordo teriam o direito de ampliar a margem de flutuação de suas moedas frente ao dólar (cujo valor em ouro estava fixado) sempre que ocorresse algum "desequilíbrio fundamental" nas contas externas. ${ }^{10}$ Como se sabe, as principais moedas européias tiveram desvalorizações superiores a 30\% nos anos do imediato pós-guerra, em função da grave escassez de dólares. Somente a partir de 1958 é que elas tornaram-se conversíveis nos termos estipulados nos atos constitutivos do Fundo. Aquela "flexibilidade" foi planejada para garantir um mecanismo adicional de ajuste do balanço de pagamentos. Complementavam tal arquitetura os controles de capitais, "[...] concebidos de maneira a evitar a ameaça em que se constituíam os fluxos de capitais voláteis, do tipo que se revelou desestabilizador nas duas décadas entre as guerras" (Eichengreen, 1996: 132), e o FMI, com recursos financeiros e mandato para penalizar países cujas políticas pudessem comprometer a estabilidade do sistema.

Em sua origem, o Acordo foi marcado por tensões que emergiram do confronto entre as propostas norte-americana e inglesa. Keynes tentou reproduzir, no plano internacional, uma arquitetura institucional que traduzisse suas preocupações em limitar o poder desestabilizador das finanças privadas (Skideslky, 1999 e 2000). No núcleo de sua proposta estava a criação de um Banco Central

\footnotetext{
${ }^{9}$ Esta perspectiva é sustentada por Eichengreen (1996, capítulo 4) e encontra amplo respaldo nos trabalhos citados na nota anterior.

${ }^{10}$ Como lembram Eichengreen (1996) e Mikessel (1996) - um dos representantes dos EUA nas negociações do Acordo - tais "desequilíbrios fundamentais" nunca foram definidos claramente.
} 
(Clearing U nion) capaz de emitir e gerir uma moeda internacional (bancor). Caberia a tal instituição o papel de regular a liquidez internacional, de modo a estabilizar os padrões de pagamento, minimizando o risco de desvalorizações/valorizações excessivas das moedas domésticas. Tal "estabilizador automático" ampliaria os graus de liberdade dos governos nacionais em realizar as políticas anticíclicas necessárias para a manutenção do pleno emprego e, assim, da estabilidade social e política, nos marcos de democracias liberais e economias de mercado. Em oposição à proposta inglesa, o Tesouro dos EUA defendeu um modelo reduzido, no qual o dólar manteve sua posição de divisa-chave. Aparentemente, os EUA não estavam dispostos a abrir mão de sua autonomia decisória em nome de um arranjo burocrático global, por mais atraente que fosse a racionalidade associada à idéia de um efetivo "prestamista em última instância" atuando na esfera internacional (Keynes, 1943, 1944).

A crise do SBW foi criando espaço para o retorno a uma ordem liberal nas finanças internacionais, ${ }^{11}$ marcada pela expansão do capital financeiro no espaço dos mercados globais, enfraquecimento do poder regulatório estatal e pela recorrência de episódios de crises financeiras ${ }^{12}$ (Helleiner, 1994, Belluzzo \& Coutinho, 1996, Strange, 1998; Solomon, 1999; Eatwell \& Taylor, 2000). Recentemente, depois do boom de afluxo de capitais privados para os mercados emergentes, entre a segunda metade dos anos 1980 e meados da década de 1990, a crise asiática (1997-1998) inaugurou uma fase de menor liquidez e maior instabilidade ${ }^{13}$. Há evidências crescentes de que a liberalização financeira tem estado no centro deste fenômeno, confirmando os temores da geração de reformadores do entre-

\footnotetext{
${ }^{11}$ Trabalhamos aqui com a inspiração de autores que partem da tradição da economia política para analisar as relações internacionais. Destaca-se nessa tradição a existência de uma tensão permanente entre a busca por autonomia decisória das forças de mercado e os imperativos políticos de sustentação de certos arranjos sociais. A conformação de uma certa ordem financeira internacional, tal qual na atual fase de "globalização financeira", aparece como sendo o resultado da interação entre os interesses privados e as decisões políticas. A haute finance, de Polany (1944), é a imagem recorrentemente trabalhada nas análises de autores como Helleiner (1994), Belluzzo \& Coutinho (1996), Chesnais (1996), Strange (1998), Eatwell \& Taylor (2000), Brenner (2002), dentre outros que, trabalham com distintas matrizes teóricas dentro da tradição da economia política. Ver também os diversos ensaios dos professores Luiz G. M. Belluzzo, Maria da Conceição Tavares, Carlos Medeiros, Franklin Serrano, Carlos Braga e outros, nos livros organizados por Fiori (2003 e 2004) e Fiori \& Tavares (1997).

${ }^{12}$ O FMI (1998) identificou, para o período 1975-97, 158 episódios de crises cambiais e 54 de crises bancárias, em uma amostra de 53 países.

${ }^{13}$ A entrada líquida de capital privado nos países em desenvolvimento atingiu seu auge em 1996, com US\$ 233 bilhões. Com a crescente instabilidade internacional, aquele montante atingiu seu menor valor absoluto desde a crise da dívida dos anos 1980: US\$ 8,9 bilhões em 2000. Esta queda deve ser atribuída à forte retração nos créditos bancários e nos fluxos de investimentos em portfólio, muito mais voláteis do que o investimento direto externo (IDE). Em termos relativos, o ano de 1996 marcou o pico da entrada líquida de capitais nos emergentes: 3,5\% do PIB conjunto destes países. A partir da crise asiática, este indicador caiu para níveis tão baixos quanto os verificados no período da crise da dívida dos anos 1980. Cálculos do autor a partir da base de dados do FMI (www.imf.org) World Economic Outlook, outubro de 2001. É bom lembrar que os anos de 2003 e 2004 foram de elevada liquidez.
} 
guerras, os arquitetos do SBW. A literatura recente tem destacado que a expansão doméstica do crédito, associada à liberalização financeira (interna e externa),está na origem dos booms nos mercados reais e financeiros. Gera-se um ambiente em que a apreciação da taxa de câmbio, a inflação no preço dos ativos financeiros e a fragilização externa - com a deterioração dos saldos em conta corrente, e redução na liquidez (ampliação da relação entre passivos e ativos externos e encurtamento das posições passivas) — podem somar-se a fatores endógenos (especialmente de origem fiscal) e exógenos (como um aumento na taxa de juros internacionais) na precipitação das crises. ${ }^{14}$

Com a retração na entrada autônoma de capitais privados nos países em desenvolvimento, o aumento da instabilidade financeira, expresso em recorrentes crises, e o questionamento sobre os pretensos vínculos automáticos entre liberalização da conta capital e crescimento econômico, o establishment oficial passou a demonstrar uma maior cautela na exposição dos custos e benefícios da liberalização financeira. Até então tal perspectiva cautelosa (ou mesmo crítica) era destacada quase que exclusivamente na tradição da economia política ${ }^{15}$. É importante lembrar que, na perspectiva do establishment, ao longo do final dos anos 1980 e início dos anos 1990, vigorou um grande otimismo acerca da globalização financeira, postura reforçada pela pressão norte-americana em torno da abertura da conta capital em vários países em desenvolvimento. $\mathrm{O}$ alerta de experts acadêmicos acerca da necessidade do estabelecimento de uma seqüência apropriada para abertura financeira foi relegado a um plano secundário (Edwards, 1995). Depois da crise mexicana e, fundamentalmente, da crise asiática, temas como a seqüência da abertura da conta capital e regulação prudencial dos sistemas financeiros domésticos voltaram à ordem do dia. A posição dos relatórios oficiais do FMI e Banco Mundial foi, com tempo, refletindo esta nova perspectiva.

Desde dentro do mainstream da academia, algumas vozes se levantaram com mais vigor na crítica aos pretensos vínculos automáticos entre liberalização financeira e expansão do lado real da economia. Rodrik (1998, 2000 e 2003) foi um dos primeiros a alertar que, no ciclo recente de globalização, a abertura financeira não estaria associada a um maior crescimento da renda. Além disso, esse autor criticou os desequilíbrios entre os custos institucionais da promoção de reformas liberalizantes e os resultados efetivos em termos de desenvolvimento (Rodrik, 2001), especialmente quando se considera que os países que não seguiram a agenda de reformas liberais emanadas de Washington e Wall Street mostraram-se os mais bem-sucedidos em termos de crescimento (Rodrik, 2003). Radalet \& Sachs (1998), Furman \& Stiglitz (1999) e Stiglitz (2002) questionaram a assimetria de resultados no processo de globalização e a "imparcialidade" do FMI na condução da gestão "política" das crises financeiras.

\footnotetext{
${ }^{14}$ Ver, dentre outros, Kaminsky et al. (1998), Demirgüç-kunt \& Detragiache (1998), IMF (1998, 2001), Aziz et al. (2000), Edison et al. (2002) e Prasad et al. (2003).

${ }^{15}$ Ver, entre outros, os trabalhos organizados por Fiori \& Tavares (1997) e Fiori (2003 e 2004).
} 
Em estudos recentes realizados no âmbito do próprio FMI tem se reforçado tal posição - mais cautelosa - quanto aos impactos potenciais dos fluxos de capitais nos países em desenvolvimento. Ao relacionar medidas de abertura financeira com indicadores de desenvolvimento econômico e dos mercados financeiros domésticos, constatou-se a existência de uma “[...] fraca relação entre crescimento e liberalização da conta capital e, como em outros estudos, tem dificuldade de encontrar relações significativas [entre crescimento e liberalização].”(IMF, 2001: 143). Ademais, a ampliação da liberalização da conta capital em muitos países em desenvolvimento teria vindo acompanhada de um aumento na volatilidade dos fluxos líquidos de capital e redução no crescimento econômico. O Fundo procurou associar esse desempenho desfavorável às falhas institucionais dos países receptores de capital. $\mathrm{Na}$ seqüência daquele trabalho, dois estudos mais amplos (Edison et al., 2002 e Prasad et al., 2003) também não encontraram vínculos sólidos entre a liberalização financeira e o crescimento dos países em desenvolvimento.

Em analogia à crise da ordem liberal anterior à constituição do SBW, pôdese notar um movimento de intenso debate nos meios acadêmico, oficial e privado em torno do que se convencionou chamar de reformas na "arquitetura financeira internacional" (AFI). Em certos momentos, a sensação foi de que o capitalismo da era pós-queda do muro de Berlim estaria seriamente ameaçado de retornar a um período de fragilidade semelhante ao da crise dos anos 1930, quando a economia real desmoronou sob o peso da derrocada das finanças. ${ }^{16} \mathrm{Em}$ um primeiro momento, o establishment oficial e privado, com o suporte analítico dos modelos teóricos de crises financeiras, adiantou-se em localizar a origem da instabilidade nas fragilidades institucionais dos países devedores, o que está refletido nos estudos do FMI citados anteriormente (Greenspan, 1997).

Nestes termos, caberia ao FMI, Banco Mundial, BIS, ao novo "Fórum de Estabilidade Financeira", dentre outros fóruns multilaterais (controlados pelo G7 e, em especial, pelos EUA) concentrar os esforços de "supervisão" do sistema, através da identificação de parâmetros de bom funcionamento dos mercados financeiros, de sua regulação prudencial pelas Autoridades Monetárias, de gestão fiscal, de transparência nas informações micro e macroeconômicas, de governança corporativa, etc. Deve-se recordar aqui, que em meio às recorrentes crises e subseqüentes megapacotes de socorro, o FMI foi fortemente questionado quanto à eficácia de suas políticas, bem como por criar risco moral sistêmico, na medida em que seus megapacotes de socorro induziriam os investidores internacionais a acreditarem que sempre seriam resgatados em caso de crises de liquidez (Meltzer, 2000 e Goldstein, 2001). Sem mandato e recursos financeiros para atuar como um efetivo "prestamista em última instância" e, principalmente, sem suporte po-

\footnotetext{
${ }^{16}$ Krugman (1999) explicita o temor ao retorno à "economia da depressão". Referências semelhantes podem ser encontradas em quase todas as análises do período, de analistas mais alinhados ao establishment (Solomon, 1999, por exemplo), insiders (Stiglitz, 2002) ou críticos (Strange, 1998; Eatwell \& Taylor, 2000).
} 
lítico dos seus acionistas majoritários para fazê-lo, ${ }^{17}$ o Fundo passou a reforçar o seu papel estatutário de monitoramento e supervisão dos países-membro de dificuldades financeiras (Krueger, 2003).

Tal agenda conservadora de reformas na AFI foi sendo apontada como insuficiente por experts da academia, do próprio mercado financeiro e de órgãos multilaterais não diretamente submetidos aos interesses do circuito WashingtonWall Street, como a Unctad e a Cepa ${ }^{18}$. Retomava-se aqui o insight original dos arquitetos do SBW, de que os mercados financeiros deveriam estar submetidos às necessidades dos governos nacionais implementarem políticas de pleno emprego no plano doméstico. Todavia, agora em um contexto de crescente interdependência na esfera internacional, as propostas de fortalecimento da AFI desta linha não convencional desembocam na idéia de se criarem instituições de caráter multilateral, capazes de melhor equilibrar as relações entre credores e devedores e, principalmente, de regular as finanças privadas. Como no passado, tais propostas envolveriam uma redução considerável nos graus de liberdade dos países credores em fazer valer seus interesses, bem como atacariam a perspectiva predominante no setor privado, que demanda uma estrutura legal enxuta e que enfatize a defesa do direito à propriedade e à livre mobilidade dos fatores (Helleiner, 1994; Strange, 1999; Stiglitz, 2002). Por isso mesmo, não contam com apoio político consistente (Eichengreen, 1996; Goldstein, 2000).

Por outro lado, notou-se um movimento interno, ao establishment, de reconhecimento de que sua própria agenda de reformas poderia ser insuficiente. A partir de uma leitura mais cautelosa sobre os efeitos da liberalização financeira, retomou-se a perspectiva de que poderiam ser válidos controles temporários sobre os capitais (especialmente na entrada), com o intuito de alterar o perfil temporal dos investimentos, de modo a reduzir sua volatilidade potencial, ou, ainda, garantir fôlego para a execução de um processo mais amplo de "modernização institucional" (Ariyosh et al.; 2000, Rogoff, 2002). E, mais, de que crises de dívida poderiam se originar do comportamento oportunista de investidores privados, de modo que países solventes no longo prazo, mas com dificuldades correntes de liquidez, poderiam ser lançados a uma crise sem poderem apelar a mecanismos como a "concordata", tão comuns na proteção de empresas e credores nos países industrializados. Surpreendentemente, o próprio FMI (Krueger, 2001) acabou levando para o centro dos debates a proposta pouco convencional, defendida há anos pela Unctad e economistas acadêmicos, de criação, na es-

\footnotetext{
${ }^{17}$ O governo Clinton (1993-2000) administrou as crises financeiras internacionais, especialmente a mexicana e a asiática, com uma política de socorro financeiro maciço numa estreita articulação Tesouro dos EUA-FMI. Já a gestão Bush (2001 até agora) mostrou-se mais sensível ao argumento do risco moral, em linha com a postura que a maioria republicana no Congresso já vinha adotando no governo anterior, qual seja, a de limitar o suporte orçamentário à capitalização do FMI com vistas a uma ampliação deste no socorro a países emergentes em crise (Stiglitz, 2002; Solomon, 2000).
}

${ }^{18}$ Cepal (2002), Eatwell \& Taylor (2000), Davidson (1992,2003), Mikesell (1996), Strange (1998), Tobin (2000), Stiglitz (2002). 
fera internacional, de mecanismos estatutários para a mediação de conflitos entre credores privados e devedores soberanos. Tal proposta foi fortemente criticada pelo setor privado e não contou com o apoio efetivo dos governos do G7. Mais uma vez é possível traçar um paralelo com o ambiente que antecedeu à constituição do Acordo de Bretton Woods. Em uma primeira versão de seu plano, Dexter White apostava em um controle muito mais disseminado e de caráter estatutário sobre os fluxos financeiros. As pressões do setor privado, especialmente dos bancos da praça de Nova Iorque, o fizeram recuar (Block, 1977; Helleiner, 1994; Boughton, 2003; Skidelsky, 2000).

\section{REFORMAS CONSERVADORAS E ESTRATÉGIAS PERIFÉRICAS}

Diante da constatação de que reformas mais profundas na AFI não deverão se concretizar em um prazo que se possa vislumbrar, Dooley et al. $(2003,2004)$ sugerem que a replicação pelos asiáticos da mesma estratégia empregada no período de vigência do SBW pelos países europeus e pelo Japão é uma solução racional de gestão política e econômica para a inserção periférica em uma economia internacional marcada pela instabilidade financeira. Por isso denomina-se aqui de "estratégia asiática" o padrão de gestão macroeconômica que tem por objetivo reduzir ao máximo o grau de exposição dos países aos efeitos perversos dos ciclos financeiros do tipo feast or famine (IMF, 2003).

Aquela estratégia tem como foco central a gestão dos fluxos financeiros em moeda forte. Implica, portanto, a utilização, combinada ou não, de vários elementos, com destaque para as restrições à livre mobilidade de capitais, como no caso da China e da Índia, a manutenção de um câmbio administrado e de um significativo drive exportador e o aumento no acúmulo de reservas oficiais. Esses elementos não convencionais completam um quadro de gestão macroeconômica marcado por um relativo conservadorismo na área fiscal e monetária, e o aprimoramento na regulamentação prudencial e nas regras de governança, em linha com as recomendações dos órgãos multilaterais. Além disso, o padrão de gestão desses elementos tem sido marcado por um sensível desvio da ortodoxia. Um caso paradigmático neste sentido é o da Coréia, que formalmente adota um regime de câmbio flutuante associado a um sistema de metas de inflação, o que não tem impedido as A.M.s de intervir, pragmaticamente, no mercado cambial com o intuito de minimizar pressões de apreciação do won e, em simultâneo, converter os saldos positivos no comércio internacional em reservas oficiais (Aizenman et al., 2004; World Bank, 2004). Como se sabe, um país que adota um regime de câmbio flutuante não teria porque intervir no mercado cambial e muito menos acumular reservas.

É importante ressaltar o aspecto pragmático da gestão dos fluxos financeiros na região, mesmo em países que têm uma tradição mais intervencionista. Isto

pôde ser notado no ano de 2003, quando a entrada líquida de capitais privados nos mercados emergentes atingiu seu maior nível desde o ano de 1996, benefi- 
ciando, particularmente, a região asiática. ${ }^{19}$ Nesse contexto da fase feast dos cada vez mais curtos ciclos financeiros, o aporte mais cuidadoso da inserção financeira da China na economia internacional não impediu que esse país sinalizasse para algumas medidas mais liberalizantes, com destaque para: (i) a redução nas restrições para a aquisição de divisas por pessoas físicas para fins de viagens internacionais de turismo; (ii) incentivos para que empresas realizem investimentos fora do país e que investidores institucionais adquiram ativos no exterior. Em contrapartida, o excesso de liquidez em moeda forte levou o governo, ao longo de 2003, a suspender, temporariamente, novos projetos de investidores institucionais estrangeiros, que estavam amparados por mecanismos de qualificação prévia. Além disso, foi estabelecido um limite diário para as pessoas físicas converterem dólares em moeda local. Da mesma forma, a Índia passou a permitir o investimento de empresas nacionais e investidores institucionais em ativos estrangeiros, o pagamento prévio de dívidas denominadas em moeda estrangeira e manutenção, por residentes, de contas denominadas em outras moedas que não a nacional. Nesse mesmo ambiente de maior liquidez, economias previamente mais abertas financeiramente, introduziram restrições regulatórias direcionadas para a minimização dos impactos potencialmente especulativos da fase feast. A Tailândia limitou empréstimos de curto prazo em bath para não residentes, e fixou limite sobre o montante e maturidade dos seus depósitos em moeda nacional. A Coréia impôs restrições, mais tarde relaxadas, sobre operações nos mercados futuros de moedas, com o intuito de reduzir a pressão especulativa contra o won (BIS, 2004; World Bank, 2004).

Tal estratégia asiática estaria contribuindo para o alcance de uma situação combinada de crescimento econômico e redução na dependência do financiamento privado de curto prazo em moeda forte. Ao destacar tal fato, Dooley et al. $(2003,2004)$ fazem eco a análises não convencionais, que nas últimas duas décadas têm se pautado em uma perspectiva mais cética quanto à capacidade da globalização econômica, especialmente em sua dimensão financeira, criar condições para o desenvolvimento com inclusão social e estabilidade macroeconômica. É interessante verificar que no período 1995-2003, que coincide com a crescente instabilidade financeira internacional e com a implantação de reformas estruturais na periferia, em especial nos países com programas de apoio financeiro do FMI e Banco Mundial, o desempenho dos países asiáticos seguiu sendo superior. que Vale dizer que, apesar da crise financeira de 1997-1998, as economias asiáticas mais desenvolvidas, como a Coréia, Hong Kong, Cingapura e Taiwan (os "NICs asiáticos", na terminologia do FMI) e os demais países em desenvolvimen-

\footnotetext{
${ }^{19}$ A entrada líquida de capitais privados nos 21 maiores "mercados emergentes" atingiu US\$ 171 bilhões, dos quais US\$ 111 bilhões foram para a Ásia, US\$ 45 bilhões em investimento direto, US\$ 36 bilhões em portfólio e US\$ 30 bilhões em outros capitais. Na América Latina, a entrada líquida foi de US\$ 16 bilhões, porém com uma queda na entrada de investimentos em portfólio e outros capitais (onde predominam os créditos bancários). Estimativas do autor, a partir dos dados do IMF World Economic Outlook Database (IMF, 2004).
} 
to da região, têm logrado crescer em um ritmo significativamente superior à média do conjunto da periferia capitalista. No período analisado, a renda per capita cresceu somente $0,6 \%$ ao ano na América Latina, contra 5,4\% nos países asiáticos em desenvolvimento e 3,6\% nos asiáticos já considerados como economias avançadas pelos órgãos multilaterais (IMF, 2004). Ademais, as políticas monetária e fiscal nas economias asiáticas são mais expansionistas do que as verificadas na América Latina, sem que isso se traduza em taxas inflacionárias mais elevadas. ${ }^{20}$ Pelo contrário, a inflação tem sido mais baixa na Ásia, 5,1\% ao ano em média, contra os $13,2 \%$ verificados nas economias latinas.

Aparentemente, a redução da vulnerabilidade externa tornou-se um aspecto central na formulação dos objetivos de gestão macroeconômica na região. Depois de flertar com a liberalização financeira, o que implicou em crescente fragilidade externa, muitas economias asiáticas passaram a ter como estratégia (implícita ou explícita) a criação de colchões de liquidez (em dólares) suficientemente elásticos para afastar o que se passou a perceber na região como um risco inerente ao processo de globalização, qual seja, a de crises financeiras geradas pela conversibilidade da conta capital. ${ }^{21} \mathrm{~A}$ idéia de que a busca de tal proteção é "racional" é admitida até por analistas contrários a essa estratégia (Eichengreen, 2004; IIF, 2004). Alguns indicadores de vulnerabilidade externa apresentaram uma melhora substantiva na Ásia. A relação reservas internacionais com respeito ao volume de importações dobrou, ao passo que quadruplicou a relação reservas e dívida de curto prazo - proxy destacada na literatura para identificar problemas de liquidez em um contexto de livre mobilidade de capitais. ${ }^{22} \mathrm{Na}$ América Latina, tais indicadores pouco se alteraram, mantendo-se em patamares significativamente reduzidos. A dívida externa com respeito ao PIB caiu em 5 pontos percentuais na Ásia (de $32 \%$ para $27 \%$ ), ao passo que aumentou em proporção semelhante na América Latina ${ }^{23}$ (de $37 \%$ para $45 \%$ ). Ademais, o custo de carre-

\footnotetext{
${ }^{20}$ Considerando-se a média do período 1995-2003, verificou-se uma expansão dos agregados monetários ampliados em 17,4\% a.a. no conjunto dos países em desenvolvimento (PEDs), de 16,6\% na Ásia em desenvolvimento (18,5\% na China e $16,5 \%$ na Índia), 14,6\% na América Latina (AL) e $11,9 \%$ nos NICs Asiáticos (Taiwan, Coréia, Cingapura e Hong Kong). No mesmo período, a média do resultado do governo central (como \% do PIB) foi de -3,2\% nos PEDs, -3,5\% na Ásia em desenvolvimento $(-2,8 \%$ na China e $-5,3 \%$ na Índia), $-2,6 \%$ na AL e $0 \%$ nos NICs asiáticos. Já a inflação teve as seguintes médias anuais: $9,8 \%$ nos PEDs, $5,1 \%$ na Ásia $(3,1 \%$ na China e $6,7 \%$ na Índia), $13,2 \%$ na AL e $2,8 \%$ nos NICs asiáticos. As estimativas são do autor com base no Anexo Estatístico de IMF (2004).

${ }^{21}$ Ver Park \& Bae (2002), Agarwala \& Prakash (2002) e Lee et al. (2002).

${ }^{22}$ Em 1995, a relação reservas/dívida de curto prazo era de 1,7 na Ásia e 1,4 na América Latina (AL). Em 2003, passou-se, respectivamente, para 8,8 e 1,6. A relação reservas/importações passou de $38 \%$ para $68 \%$ na Ásia, e de $51 \%$ para $48 \%$ na AL, tendo 2002 como ano de ponta. Estimativas do autor com base no Anexo Estatístico de IMF (2004). O bom desempenho das contas externas da maior parte dos países latinos, em 2004, deverá melhorar tais indicadores. Ainda assim, o desempenho asiático seguiu sendo superior.

${ }^{23}$ Neste caso, o peso do bom desempenho de Índia e China faz diferença, na medida em que as economias asiáticas em desenvolvimento, quando analisadas sem aqueles, apresentaram um incremento daquela relação.
} 
gamento da dívida externa (juros e amortizações sobre o estoque de dívida) é quase três vezes maior entre as economias latino-americanas - pouco mais de 2\% na média do período na Ásia, contra 6\% na América Latina.

É possível identificar distintos padrões de ajuste das contas externas a partir da mudança no ciclo financeiro internacional. Se antes da crise asiática as economias avançadas e em desenvolvimento da região estavam absorvendo um "excesso de poupança externa", que tinha por contrapartida déficits estruturais em conta corrente, depois de 1997 evidenciou-se um significativo ajuste, nos moldes analisados por Dooley et al. (2003, 2004). Os superávits nas transações de bens e serviços permitiram compensar a saída líquida de capitais privados do período mais grave de instabilidade e, ainda, gerar um acúmulo substantivo de reservas internacionais. Já em 1997, a conta corrente dos NICs asiáticos e da Ásia em Desenvolvimento tornou-se positiva, com um resultado acumulado de US\$ 670 bilhões até 2003. No mesmo período, a América Latina manteve uma posição deficitária (acumulada em US\$ 340 bilhões), ainda que a partir de 2002 a retração econômica (em um primeiro momento) e o drive exportador (especialmente nos casos argentino e brasileiro) tenham permitido uma reversão nos déficits. $\mathrm{Na}$ Ásia, mesmo em países que formalmente adotam regimes de câmbio flexível, como a Coréia, percebe-se a iniciativa governamental de transformar os saldos cambiais favoráveis em reservas oficiais. É possível estimar que as reservas cambiais da Ásia quase triplicaram nos anos que se seguiram à crise de 1997, estando hoje — segundo semestre de 2004 - em um patamar próximo a US\$1,3 trilhão, excluindo o Japão. Para se colocar em perspectiva, as reservas das principais economias latino-americanas que estavam na casa de US\$ 141 bilhões, em 1996, passaram para US\$ 179 bilhões, em março de 2004. No mesmo período, os asiáticos passaram de US\$ 477 bilhões para US\$ 1,3 trilhão (Dooley et al., 2003, 2004; BIS, 2004).

Os saldos comerciais favoráveis e o retorno dos capitais privados à região têm pressionado os mercados cambiais no sentido de uma apreciação das taxas nominais de câmbio. Há uma diversidade de regimes cambiais na Ásia, em um espectro que vai do currency board de Hong Kong e do câmbio fixo da Malásia, a regimes de câmbio flutuante de jure, que na prática são "administrados". As intervenções nos mercados cambiais têm sido uma constante. Aparentemente, as A.M.s buscam minimizar os efeitos da queda do dólar no mercado internacional. É interessante notar que, entre o começo de 2002 e de 2004, a moeda norte-americana chegou a perder entre $40 \%$ e $50 \%$ no seu valor, em termos nominais (entre $10 \%$ e $25 \%$ em termos reais e considerando-se as ponderações dos fluxos de comércio), com respeito ao euro e as moedas de outros parceiros comerciais importantes dos EUA, como Canadá e Austrália, ao passo que as moedas asiáticas subiram muito menos - desde a posição fixa das moedas chinesa e malaia, passando pela depreciação do peso filipino, até apreciações moderadas entre $5 \%$ e $20 \%$ nos demais casos. O esforço oficial para evitar flutuações significativas nas taxas de câmbio tem se traduzido no aumento das reservas externas, que por sua vez tendem a resultar em medidas de esterilização do excesso de crédito domésti- 
co (Bergsten, 2004; World Bank, 2004; BIS, 2004; Aizenman et al., 2004; Eichengreen, 2004).

No caso asiático, no período 2001-2004, a variação de reservas como proporção da renda atingiu o nível médio mais elevado das últimas quatro décadas, algo em torno de $5 \%$, contra uma média pouco superior a $1 \%$ do período 1970 $2000 .^{24}$ Tal nível também não encontra precedentes quando se compara o desempenho corrente ou histórico de outras regiões. A maior parte dos analistas ${ }^{25}$ sugere que este acúmulo estaria associado à combinação de pelo menos três fatores centrais: (i) o significativo drive exportador, que é um elemento que vem caracterizando o padrão de desenvolvimento dos países da região, e que foi potencializado pela recente recuperação da economia norte-americana e pelo dinamismo chinês (que vem respondendo por cerca de $1 / 3$ do crescimento da demanda mundial); (ii) a maior liquidez financeira internacional; e (iii) as estratégias das A.M.s locais de minimizar as pressões de apreciação das moedas locais. Todavia, como pontuam Eichengeen (2004) e Dooley et al. (2003), parece haver uma racionalidade adicional vinculada à busca de "proteção" ante a um ambiente financeiro internacional cada vez mais liberalizado e desregulamentado e, por isso mesmo, volátil.

É importante lembrar que a crise financeira de 1997-1998 causou um profundo trauma, na medida em que expôs a fragilidade da estratégia de liberalização financeira dos anos 1990. A maioria dos países da região havia reduzido os mecanismos de controle dos movimentos de entrada e saída de capitais. Facilitou-se e, em muitos casos, incentivou-se, a troca do funding doméstico pelo externo. O boom de investimentos, reais e nos mercados de capitais, foi alimentado pela poupança externa ${ }^{26}$, mesmo que os níveis de poupança interna excedessem a casa dos $30 \%$ do PIB. A ausência de uma estrutura eficiente de regulação dos mercados financeiros e a disseminação de políticas hands off, em uma orientação oposta às políticas desenvolvimentistas do passado recente, contribuíram para a criação de um ambiente institucional inadequado (Unctad, 1998; Radalet \& Sachs, 1998; Stiglitz, 2002).

Ademais, os pacotes de socorro dos órgãos oficiais vieram acompanhados de condicionalidades até então pouco usuais, que envolviam reformas nos sistemas financeiros, reorganização dos padrões de governança corporativa, redefinição do escopo de políticas setoriais, etc. O grau de ingerência sob as políticas domésticas ultrapassou os limites tradicionais das esferas monetária e fiscal, causando desconforto em vários governos locais (Stiglitz, 2002; Escap, 2002). Desde então, os policymakers asiáticos vêm dando sinais de que não pretendem reprodu-

\footnotetext{
${ }^{24}$ Estimativas do autor com base nos dados de diversos World Economic Outlook Database, disponibilizados em www.imf.org.

${ }^{25}$ Ver, dentre outros, Bergsten (2004), World Bank (2004) e BIS (2004).

${ }^{26}$ Em 1995 e 1996, as EACs receberam cerca de US\$ 130 bilhões em fluxos líquidos de capitais privados, eqüivalendo a $6 \%$ do PIB dos cincos países, em média (estimativas do autor a partir dos dados da base do World Economic Outlook, dezembro de 2001 — www.imf.org).
} 
zir estratégias passivas de inserção nos mercados financeiros internacionais. Assim, por exemplo, em reação à crise e aos pacotes oficiais, o governo japonês sugeriu a criação de um Fundo Monetário Asiático. Ainda que esta idéia tenha sido abortada por pressões externas, a crise criou condições para o aprofundamento da discussão regional visando criar canais formais para a coordenação das ações das Autoridades Monetárias (AMs). O mecanismo de swap cambial firmado em 2000 entre os países da ASEAN $^{27}$ com Coréia, Japão e China, denominado Iniciativa de Chiang Mai e a emissão coletiva de bônus internacionais denominados em várias moedas locais, chamada de Asia Bond Market Initiative, foram passos adicionais na direção de uma maior integração financeira na região (Park \& Bae, 2002; Agarwala \& Prakash, 2002; World Bank, 2004).

\section{CONSIDERAÇÕES FINAIS}

Há uma estratégia periférica asiática "vencedora" neste período pós-crise financeira de 1997-1998? Não há uma resposta unívoca aqui, assim como é razoável admitir que não havia um único modelo asiático de desenvolvimento. $\mathrm{O}$ que se pode afirmar é que os principais países da região, com distintos arcabouços macroeconômicos, especialmente no que se refere aos regimes monetáriocambiais, têm perseguido, de forma bem-sucedida até aqui, reduzir a exposição de suas economias aos efeitos dos ciclos financeiros do tipo feast or famine. Isto tem implicado na combinação de políticas pouco alinhadas aos interesses do circuito Washington - Wall-Street, como as intervenções maciças nos mercados cambiais, pela compra de ativos denominados na moeda norte-americana, em uma proporção que não encontra precedentes na história recente das finanças internacionais. Não à toa, as vozes mais identificadas com o establishment financeiro, como Goldstein (2003), Bergsten (2004), Eichengreen (2004), IIF (2004), para citar os mais representativos, têm criticado fortemente tal "estratégia asiática”, pejorativamente chamada de mercantilista.

Todavia, como é reconhecido por aqueles mesmos analistas, aquela estratégia visa não só preservar a competitividade externa dos países da região, como, também, funciona como uma proteção contra um ambiente externo de volatilidade. Mais explicitamente: "[...] além de preservar uma posição favorável de competitividade externa... a intervenção requerida para viabilizar as políticas atuais levou a uma elevação das reservas cambiais, que é vista por muitos governos da região como um remédio perfeito para isolar suas economias da inconstância das finanças internacionais" (IIF, 2004: 7). Assim, seria legítimo considerar que, ao evitar uma reposição da situação de vulnerabilidade externa que levou à crise, as políticas de gestão dos fluxos financeiros que compõem o que aqui denominamos de

${ }^{227}$ Association of South-East Asian Nations: Indonésia, Malásia, Tailândia, Filipinas, Cingapura, Laos, Brunei, Camboja, Vietnã e Miamar. 
"estratégia asiática" encontram um amparo de racionalidade, que vai ao encontro dos fatos estilizados detectados pelas pesquisas mais recentes do próprio FMI (IMF, 2001; Edison et al., 2002 e Prasad et al., 2003), onde a liberalização financeira aparece mais como uma fonte de instabilidade do que de crescimento. Aqui é importante lembrar que a ausência de um vínculo automático entre a globalização financeira e o crescimento econômico com estabilidade macroeconômica e coesão social é um tema central nos trabalhos de autores que pertencem à tradição crítica da economia política (Fiori \& Tavares, 1997; Fiori, 2003 e 2004).

Mas quais os custos dessa estratégia? Os críticos supracitados lembram que ao preservar artificialmente o valor externo de suas moedas, através de uma intervenção maciça nos mercados cambiais, as economias asiáticas estariam dificultando o equacionamento dos desequilíbrios externos da economia norte-americana, cujo déficit em transações corrente já está próximo a $5 \%$ do PIB. Se o dólar teria perdido algo entre $40 \%$ e $50 \%$ do seu valor frente ao euro, nos últimos dois anos, a queda da taxa de câmbio real e efetiva teria ficado em cerca de $10 \%$, algo insuficiente para viabilizar um ajuste mais expressivo das contas externas dos EUA. Além disso, o peso do ajuste cambial teria recaído de forma desproporcionalmente maior sobre a Europa, Austrália e Canadá. Além disso, em uma perspectiva asiática, o acúmulo de reservas oficiais teria pelo menos duas contrapartidas de médio e longo prazo: a perda potencial de eficiência e bem-estar pela redução artificial do potencial de importações de bens de capital e de consumo, e o efeito fiscal expansionista das políticas de esterilização.

Em uma outra perspectiva, Davidson (2003) insiste na necessidade de reformas profundas na arquitetura financeira internacional AFI e aponta para a tendência de que a estratégia de acumulação de reservas internacionais gere um equilíbrio global com desemprego. Considera que as medidas convencionais de reforma na AFI não são suficientes para equacionar o principal problema da economia internacional, vale dizer, a tendência à cristalização de uma situação estrutural de desemprego por insuficiência de demanda efetiva. Em sua perspectiva, a economia internacional pode ser compreendida como uma "economia fechada" nos mesmos termos análise de Keynes na Teoria Geral, onde o aumento exacerbado na preferência pela liquidez pode gerar (mesmo quando os preços são flexíveis) uma situação de equilíbrio com desemprego. Como alternativa, Davidson defende a criação de uma moeda internacional que não seja passível de entesouramento pelos agentes privados e que seria gerida por uma autoridade monetária supranacional. O objetivo, análogo ao desenvolvido por Keynes (1943) no período que antecedeu o Acordo de Bretton Woods, é o de limitar o poder das finanças privadas e ampliar o grau de liberdade para os governos nacionais perseguirem políticas de pleno emprego.

Apesar da pertinência das observações de Davidson (2003), constatou-se aqui que as reformas na AFI foram limitadas e marcadas por um viés conservador, com o predomínio dos interesses dos países credores, ou mais especificamente, das finanças privadas. Nestes termos, Bresser-Pereira \& Nakano (2002), Rodrik (2003), Dooley et al. (2003, 2004), dentre outros, sustentam que os países 
em desenvolvimento mais bem-sucedidos em ganhar graus de autonomia na realização de estratégias de crescimento são exatamente os que estão conseguindo contrabalançar o poder das finanças privadas internacionais. Procurou-se destacar neste trabalho que há evidências de que as economias asiáticas em desenvolvimento conseguiram sustentar taxas elevadas de crescimento da renda com a utilização de políticas monetária e fiscal menos estreitas, mesmo em um ambiente de maior instabilidade. Ao contrário, a América Latina sucumbiu às crises financeiras da segunda metade da década de 1990. Argumentou-se aqui que a busca ativa de redução da vulnerabilidade externa, através da gestão dos fluxos de capitais e taxas de câmbio, é um dos elementos que ajudam a compreender o sucesso asiático recente. Ao passo que a dependência estrutural de financiamento externo fez das economias latinas alvos fáceis das pressões oficiais e privadas em torno da implementação de políticas contracionistas.

\section{REFERÊNCIAS BIBLIOGRÁFICAS}

AGARWALA, R.; PRAKASH, B. (2002). Regional Cooperation in Asia: Long Term Progress, Recent Retrogression, and Way Forward. ERD Working Paper Series, n. 28. Manila: Asia Development Bank.

AIZENMAN, J.; LEE, Y.; RHEE, Y. (2004). “International Reserves Management and Capital Mobility in a Volatile World: policy considerations and case study of Korea”. N BER Working Paper 10.534. Cambridge, Mass.: National Bureau of Economic Research.

ARIYOSHI, A.; HABERMEIER, K.; LAURENS, B.; OTKER-ROBE, I.; CANALES-KRILJENKO, J.I.; KIRILENKO, A. (2000). "Capital Controls: Country Experiences with Their Use and Liberalization”. I M F O ccasional Paper No. 190. Washington, DC: International Monetary Fund.

AZIZ, J.; CARAMAZZA, F.; SALGADO, R. (2000). "Currency Crises: In Search of Common Elements”. IM F Working Paper, WP/00/67. Washington, DC: International Monetary Fund.

BELLUZZO, L.G. M.; COUTINHO, L. "Desenvolvimento e estabilização sob finanças globalizadas”. E conomia e Sociedade, n 7. Campinas: Instituto de Economia/Unicamp, 1996.

BERGSTEN, F. (2004). The IMF and Exchange Rates. "Testimony before the Committee on Banking, Housing, and Urban Affairs United States Senate”. May 19. Washington, DC: Institute for International Economics. Disponível em:www.iie.com (acessado em 31/05/2004).

BRENNER, R. (2002). Boom and the Bubble. The US in the World Economy. London: Verso Press.

BRESSER-PEREIRA, L.C.; NAKANO, Y. (2003). “Crescimento econômico com poupança externa?” R evista de Economia Política, Vol. 23, n 2, Abr-Jun.

BIS (2004). 74 ${ }^{\text {th }}$ Annual Report. Basle: Bank for International Settlements.

BLOCK, F. (1977). The O rigins of I nternational E conomic D isorder. Berkeley: University of California Press.

BOUGHTON, J.M. (2002). "Why White, Not Keynes? Inventing the Postwar International Monetary System”. I M F Working Paper, 02/52. Washington: International Monetary Fund.

CEPAL (2002). G row th with Stability: financing for development in the new international context. Santiago, Chile: Comissión Económica para America Latina y Caribe.

CHESNAIS, F. (1996). A mundialização do capital. São Paulo: Xamã.

DAVIDSON, P. (2003). "The Future of International Financial System”. Conference on the Future of Economics, Cambridge University, September, 18.

DE CECCO, M. (1979). “The Origins of Postwar Payments System”. Cambridge Journal of E conomics, 3, pp. 49-61.

DOOLEY, M. P.; FOLKERTS-LANDAU, D.; GARBER, P (2003). “An Essay on the Revived Bretton 
Woods System". Cambridge, Mass.: National Bureau of Economic Research (N BE R Working Paper n. 9971).

(2004). "The Revived Bretton Woods System: the effects of periphery intervention and reserve management on interest rates and exchange rates in center countries". Cambridge, Mass.: National Bureau of Economic Research (N BER Working Paper n. 10.332)

EATWELL, J. ; TAYLOR, L. (2000). G lobal Finance at Risk. New York: The New Press.

EDISON, H.; KLEIN, M., RICCI, L.; SLOK, T. (2002). Capital Account Liberalization and Economic Performance: a review of the literature. I M F Working Paper 02/120. Washington, DC: International Monetary Fund.

EDWARDS, S. (1995). Capital Controls, Exchange Rate and Monetary Policy in the World Economy. Cambridge, Mass.: Cambridge University Press.

EICHENGREEN, B. (1996). G lobalizing Capital: a history of the international monetary system. Princeton: Princeton University Press (edição brasileira da Editora 34, São Paulo, 2000).

. (1999)."Toward a New International Financial Architecture: A Practical Post-Asia Agenda”. Institute for International Economics.

(2004). "Global Imbalances and the Lessons of Bretton Woods". N BER Working Papers 10.497. Cambridge, Mass.: National Bureau of Economic Research.

ESCAP (2002). "Bulletin on Asia-Pacific Perspectives 2002/2003: Sustaining Growth Amidst Uncertainties". Bangkok: United Nations Economic and Social Commission for Asia and Pacific. Disponível no site:www.unescap.org.

FIORI, J.L. (2003). Estados e moedas no desenvolvimento das nações. Petrópolis, Vozes. (2004). O poder americano. Petrópolis, Vozes.

FIORI, J.L, TAVARES, M.C. (1997). Poder e Dinheiro. Petrópolis, Vozes.

FISCHER, S. (1999). O $\mathrm{n}$ the $\mathrm{N}$ eed of I nternational L ender of L ast R esort. Washington: International Monetary Fund.

FURMAN, J.; STIGLITZ, J.E. (1998). "Economic Crises: Evidence and Insights from East Asia”. Brookings Papers on Economic Activity, n.2, p. 1-135. Washington: Brookings Institution.

GOLDSTEIN, M. (2001). An Evaluation on Proposals to Reform on International Financial Architecture. NBER Conference on Management of Currency Crises.

. (2003). "China's Exchange Rate Regime. Testimony before the Subcommittee on Domestic and International Monetary Policy, Trade, and Technology". Committee on Financial Services, US House of Representatives, October, 1. Washington, DC: Institute for International Economics. Disponível em: www.iie.com (acessado em 31/05/2004).

GREENSPAN, A. (1997). Remarks by Chairman Alan Greenspan at the Economic Club of New York, NY (december, 2).

HELLEINER, E. (1994). States and the Reemergence of G lobal Finance: from Bretton Woods to the 1990s. Ithaca:Cornell University Press.

IIF (2004). Regional O verview: A sia. Washington, DC: Institute of International Finance.

IMF (1998). World Economic Outlook, may. Washington, DC: International Monetary Fund. . (2001). World Economic Outlook, october. Washington: International Monetary Fund. . (2002). World Economic Outlook, may. Washington: International Monetary Fund. . (2003). Global Financial Stability Report, march. Washington: International Monetary Fund. . (2004). World Economic Outlook, may. Washington: International Monetary Fund.

IMFC (2003). Communiqué of the International Monetary and Financial Committee, Board of Governors of the International Monetary Fund, April $12^{\text {th }}$.

JOMO, K.S. (1996) Lessons from Growth and Structural Change in the Second-tier South East Asian Newly Industrialized Countries. Project "East Asian Development: Lessons For a New Global Environment". Geneve: United Nations (UNCTAD).

KAMINSKY, G.; LIZONDO, S.; REINHART, C. (1998). Leading Indicators of Currency Crisis. Washington DC: IMF (mimeo).

KEYNES, J. M. (1943). “The International Clearing Union”. In HARRIS, S. E. (1950, org.). The N ew E conomics: Keynes Influence on Theory and Public Policies. New York: Alfred A. Knopf. Reproduzido em português em: SZMRECSÁNYI, T. (1978). J ohn M aynard K eynes: economia. São Paulo: Ática. 
. (1944). “The International Monetary Fund”. In HARRIS, S.E. (1950, org.). The N ew E conomics: Keynes Influence on Theory and Public Policies. New York: Alfred A. Knopf. Reproduzido em português em: SZMRECSÁNYI, T. (1978). John M aynard K eynes: economia. São Paulo: Ática.

KINDLEBERGER, C. H. (2000). M anias, pânicos e crashes, $3^{\mathrm{a}}$ ed. Rio de Janeiro: Nova Fronteira.

KRUEGER, A. O. (2001). International Financial Architecture for 2002: A New Approach to Sovereign Debt Restructuring. Speech at the National Economists' Club Annual Members' Dinner American Enterprise Institute, Washington DC.

. (2003). "Detecting and Preventing Financial Crises - Recent IMF Approaches". Speech at the Bretton Woods Committee Annual Meeting U.S. State Department.

KRUGMAN, P. (1999). U ma nova recessão? O que deu de errado? São Paulo: Editora Campus.

LASTRA, R. M. (2000). "The International Monetary Fund in Historical Perspective". Journal of International Economic Law, p.507-523.Oxford: Oxford University Press.

LEE, J.; PARK, Y. C.; SHIN, K. (2002). “A Currency Union in East Asia”. (mimeo). Disponível em http://soback.kornet.net/ ycpark/

MADDISON, A. (2001). The World E conomy: a millennial perspective. Paris: OECD.

MELTZER, A. H. (2000 - Chairman). Report of the International Financial Institution Advisory Comission. Washington, DC: International Financial Institution Advisory Comission.

MIKESELL, R. F. (1996). Revisiting Bretton Woods. Public policy Brief, n. 24. The Jeremy Levy Economics Institute.

MINSKY, H. P. (1991). “The Financial Instability Hypothesis: a Clarification”. . In FELDSTEIN, Martin (1991). The Risk of E conomic Crisis. Chicago: The University of Chicago Press.

PARK, Y. C., BAE, K. (2002). Financial Liberalization and Economic Integration in East Asia. PECC Financial Forum Conference "Issues and Prospects for Regional Cooperation for Financial Stability and Development", Honolulu, august.

PRASAD, E., ROGOFF, K., WEI, S., KOSE, M.A (2003). Effects of Financial Globalization on Developing Countries: Some Empirical Evidence.

POLANYI, K (1944). The Great Transformation (tradução para o português da Editora Elsevier, 9a ed., 2000).

RADALET, S.; SACHS, J. D (1998). "The East Asian Financial Crisis: Diagnosis, Remedies, Prospects". Brookings Papers on Economic Activity, n.1. Washington, DC: Brookings Institution.

RODRIK, D. (1998). "Who Needs Capital-Account Convertibility?” (http://ksghome.harvard. edu/ .drodrik.academic.ksg/papers.html)

(2001). “The Developing Countries Hazardous Obsession with Global Integration”. (http://ksghome.harvard.edu/ .drodrik.academic.ksg/papers.html)

. (2003). "Growth Strategies". Disponível em: http://ksghome.harvard.edu/ .drodrik.academic.ksg/papers.html.

ROGOFF, K. (2002). Rethinking Capital Controls: When Should We Keep an Open Mind? Finance and D evelopment, v. 39, n. 4. Washington, DC: IMF.

SKIDELSKY, R. (2000). John M aynard Keynes: fighting for Britain, 1937-1946. London: MacMillan.

SOLOMON, R. (1999). M oney on the M ove: the revolution in international finance since 1980. Princeton: Princeton University Press.

STIGLITZ, J. E. (2002). A globalização e seus malefícios. São Paulo: Futura.

STRANGE, S. (1998). M ad M oney: when markets outgrow governments. The University of Michigan Press.

TOBIN, J. (2000). "Financial Globalization”. World D evelopment, v. 28, n. 6, pp. 1101- 04.

UNCTAD (1998). Trade and Development Report, 1998. Genebra: United Nations Conference on Trade and Development - United Nations.

WORLD BANK (1993). The East Asian Miracle. Washington, DC: World Bank. . (2000). Global Development Finance, 2000. Washington, DC: World Bank. (2001). Globalization, Growth and Poverty. Washington, DC: World Bank. . (2004). East Asian Up Date, april. Washington, DC: World Bank. 